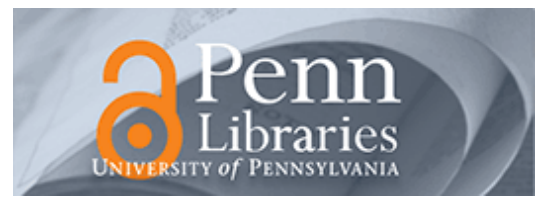

Studies in Visual Communication

Volume 7

Issue 1 Winter 1981

Article 5

1981

\title{
Performance and Reality: Interpretation of Observed Behavior in Dreams, Hysteria, and Hypnosis
}

Aaron Honori Katcher

\section{Recommended Citation}

Katcher, A. H. (1981). Performance and Reality: Interpretation of Observed Behavior in Dreams, Hysteria, and Hypnosis. 7(1), 63-73. Retrieved from https://repository.upenn.edu/svc/vol7/iss1/5

This paper is posted at ScholarlyCommons. https://repository.upenn.edu/svc/vol7/iss1/5

For more information, please contact repository@pobox.upenn.edu. 
Performance and Reality: Interpretation of Observed Behavior in Dreams, Hysteria, and Hypnosis 


\section{Performance and Reality: Interpretation of Observed Behavior in Dreams, Hysteria, and Hypnosis}

\section{Aaron Honori Katcher}

The themes of this paper arose within a long series of conversations with Sol Worth. The talks were informal, a part of long, rambling walks through the University of Pennsylvania campus. These talks were a continuing seminar introducing me to ideas about the way in which we extract meaning from the visual world. The most recurrent theme was the therapeutic dream, the dream that becomes the focus of the patient's and the analyst's inquiry. Investigation of the dream brought us to the problem of intentand, indeed, the meaning of the concept "intent" - when the unconscious mind was assumed to be the origin of a particular event, as in the case of dreams. Questions of intent led to considerations of situations in which there was a problem in distinguishing simulated emotion or behavior from "real behavior," problems inherent to the understanding of feigned illness in hysteria, the behavior of confidence men and spies, and even the behavior of the hypnotized subject. Unfortunately Worth's death left me with only our notes for an initial paper, and I have had to develop our once mutual thoughts alone and uncertainly in a novel field of inquiry. Regretfully I must take responsibility for the argument inherent in this paper, and hope that some of the value of the dialogue that preceded this effort remains.

\section{The Therapeutic Dream}

The therapeutic dream is a construction of the patient and his or her analyst, and has in its initial and final telling only a tenuous relationship to the psychic events that occurred simultaneously with periods of rapid eye movements on the night previous to the therapeutic hour.

Since the dream is constructed as a communication by both the analyst and the patient, it appears to have little necessary relationship to the psychophysiological events we recognize as a "dream. " What then is the proper interpretive strategy for understanding the meaning of a dream? One appropriate to a communication such as a patient narrating a dream to an analyst and augmenting that narrative with his associative memories? Or one appropriate to a psychobiological event like a subject being awakened after a period of rapid eye movement sleep in a laboratory, and asked to rapidly recount his dream to a recorder? This question was important to Worth, because of his differentiation between strategies used to decipher interactive events and communications (Worth and Gross 1974). Communication was defined by Worth as a class of events in which the observer made an assumption that there was an intent to communicate. Such communications were deciphered by the use of inferential strategies,

Aaron H. Katcher is Associate Professor of Psychiatry in the School of Medicine and the School of Dental

Medicine, University of Pennsylvania. dependent upon the context, structure, or grammar of the entire event. Natural events, signs, or interactions were deciphered by the use of attribution, that is, recognition of invariant rather than context-dependent meanings of individual elements of the event.

Communication therefore is defined as a social process, within a context, in which signs are produced and transmitted, perceived and treated as messages, from which meaning can be inferred.

Let us review briefly some of the terms we have introduced earlier and place them within the context of communication. The concept of articulation and interpretation must be seen as relevant to both the production and transmission of signs as well as to the perception and subsequent treatment of them. While the perception and subsequent treatment of symbolic events might be thought of as acts of interpretation, and production and transmission seen as acts of articulation, they can most fruitfully be seen as parts of a process which could be called articulation/interpretation. This process will be further explained as being similar to what we are calling implication/inference.

We will subsequently argue that the implication/inference process cannot take place without an assumption of intention on both the part of the articulator as well as the interpreter. [Worth and Gross 1974]

Dreams trouble us not only because they seem like unintended events, forced upon us by the operation of some part of our brain quite different from that which rules our conscious state, but yet must be shaped into some kind of clearly intended narrative to be studied; they also are problematical in their interpretation because they are essentially pictures which must be interpreted as narrative, as verbal descriptions. We tell others our dreams; we do not draw them for others. Worth argued that there were important distinctions between pictorial art and verbal communication. In "Pictures Can't Say Ain't' he stated:

pictures and speech are different precisely because pictures are not a language in the verbal sense. That while words mean primarily or basically because of lexicon and syntax, pictures have no lexicon (in the dictionary sense) nor a syntax in the formal grammarian sense. And yet I am suggesting that we can interpret meaning from pictures. It is clear, however, that if pictures have no grammar in the strict linguistic sense, they have something like it: they have form, structure, conventions and rules. It is clear that even though a theory of correspondence is not sufficient to deal with the truth in pictures, pictures must nonetheless correspond to something. Even the most un- or non-representational painting must refer to something or it would make no sense at all. Although attributional strategies are convenient for the unskilled, no picture maker likes to think his picture is totally up for grabs.

Earlier I suggested that the strategies we employ to interpret meaning from pictures-that is, how pictures meanare largely responsible for what pictures mean. I have suggested that if we use attributional strategies, pictures can mean almost anything. 
If, on the other hand, we use communicational strategies, a particular set of meanings can be developed for pictures as well as for that which we have often defined as art. In general what we imply and infer through pictures are: first, an existential awareness of particular objects, persons, and events that are ordered, patterned, sequenced, and structured so as to imply meaning by the use of specific conventions, codes, schemata, and structures. [Worth 1975]

In this paper I argue that the problem of intent in the interpretation of human behavior is compounded by a difference between the way in which we evaluate words and the way in which we evaluate pictures, like the "pictures" in a dream or the visual records of human behavior such as alteration of body posture, disturbances of movement, facial expression, or the altered appearance of a subject in a deep hypnotic trance. Those aspects of behavior that we see or observe as having no recourse to words are almost always accepted as signs of the operation of an unintentional causal event, a response to an experimental stimulus, with much less suspicion than words would be. Since everyone recognizes that it is not possible to "cause" a sentence, observed behavior is favored over words as evidence of the operation of psychological causality. Moreover, any behavior we observe can, by the simple mechanism of changing the sensitivity of the observing instrument, be reduced to behavior that is clearly unintended. So, for example, the motions of a skilled actor can be reduced to very minute facial flickers with high-speed photography, and these flickers studied as unintentional behavior. Words, however, are clearly and unequivocally distinguishable from the character of the voice or the hand that produces them. Thus human behavior that is observed visually produces the same inherent problem of interpretation as the images of the dream, even though such observed behavior need not be translated into words to make it part of a social process.

We can begin the investigation of how we make assumptions about intent and causality, in giving meaning to dreams and the phenomena of hypnosis and hysteria, by noting that Darwin struggled with the same problem of differentiating intended or willed emotive behavior from innate behavior.

\section{Intention and Causality}

In The Expression of the Emotions in Man and Animals Darwin builds a persuasive argument that emotional expression is largely determined by inherited and hence innate patterns of behavior which are not subject to the action of intent or the will. Yet in a very curious passage in his concluding remarks he introduces will, intent, and conscious simulation of emotion:
The free expression by outward signs of an emotion intensifies it. On the other hand, the repression, as far as this is possible, of all outward signs softens our emotions. He who gives way to violent gestures will increase his rage; he who does not control the signs of fear will experience fear in a greater degree; ... .

Even the simulation of an emotion tends to arouse it in our minds. [Darwin 1965 ed.: 365]

Darwin then goes on to quote the first paragraph of Hamlet's soliloquy "Oh, What a Rogue and Peasant Slave Am I." 'That soliloquy is worth considering in detail because it is concerned with the distinctions between signs and symbolic acts, between caused interactions and intended communications, between stimuli and articulated events, and between responses and interpretations:

Is it not monstrous that this player here,

But in a fiction, a dream of passion,

Could force his soul so to his own conceit

That from her working all his visage wan'd;

Tears in his eyes, distraction in's aspect,

A broken voice, and his whole function suiting

With forms to his conceit? And all for nothing!

For Hecuba?

What's Hecuba to him or he to Hecuba,

That he should weep for her? What would he do,

Had he the motive and the cue for passion

That I have? He would drown the state with tears, And cleave the general ear with horrid speech;

Make mad the guilty, and appall the free;

Confound the ignorant and amaze indeed,

The very faculties of eyes and ears.

Yet I,

A dull and muddy-mettled rascal, peak

Like John-a-dreams, unpregnant of my cause,

And can say nothing; .

Why, what an ass am I! This is most brave, That I, the son of a dear father murder'd Prompted to my revenge by heaven and hell, Must, like a whore, unpack my heart with words And fall a-cursing...

I have heard

That guilty creatures, sitting at a play, Have by the very cunning of the scene Been struck so to the soul that presently They have proclaim'd their malefactions; For murder, though it have no tongue, will speak With most miraculous organ. I'll have these players Play something like the murder of my father Before mine uncle: I'll observe his looks; I'll tent him to the quick: If he but blench, I know my course...

the play's the thing Wherein I'll catch the conscience of the king. [Shakespeare 1965 ed.: 1087] 
Hamlet clearly distinguishes between real feeling and the fictitious emotion of the player, emotion which he describes as consciously intended-his soul forced to his own conceit. The intended emotion which excited his wonder is mimicked behavior, not words. Hamlet now wonders at visual displays, "wan'd" visage, tears, and distracted facial expression. He wonders at the change in form or representation worked by the intent of the player. The player's conceit, that is "intent," changes his usual form.

In the second paragraph, he contrasts the actor's performance with an imaginary natural or "caused" event. He imagines what would happen if that actor had a true cause for his feeling, or "motive and the cue for passion." That real emotion would then have very large emotional effects on the audience, causing equally real and large responses-the same augmentive effects that Darwin speaks of when he refers to the power of simulated emotion. Hamlet, much like modern psychophysiological investigators, talks of emotion as both stimulus and response. Hamlet describes the effect of intense motivation (the murder of a father) on emotional display and postulates a testable hypothesis which predicts the results of that display on two classes of respondents, the "guilty" and the "free."

Later, the emotive display of the actor charged with "real" motivation is contrasted with his own behavior. He uses that contrast to make a distinction between words and observable behaviors, between lexical and representational events. He chides himself for responding only in words, just as he marveled at the actor's capacity to respond with a visual display. The contrast between visual events is a critical distinction in Hamlet's psychobiology, just as it is in modern psychological investigation. Words can never be just natural events; they are always subject to the intent of the speaker (except in certain cases where they were clearly unintended, as in slips of the tongue and other psychopathologies of everyday life). Eehavior can always be, Hamlet tells us, either a natural or a performed event. We are quite comfortable in accepting behaviors, visual displays, and pictures as natural events, just as we are always uncomfortable and suspicious when we look at words as signs of causal events or interactions. So Hamlet, like us, suspicious of words, scolds himself for showing emotion "unpacking his heart" not with a change in form or behavior but with words.

In the last paragraph of the soliloquy Hamlet decides to use a play as a stimulus and perform a real psychophysiological experiment of similar structure to the imaginary one described in the second paragraph. Only, the stimulus in this experiment is feigned emotion-a play, a communication-not a caused or motivated emotional response. The play used by Hamlet as a stimulus is a "dumb show," a play without words or a mime performance with only emotional display and representational acts to serve as stimuli. Thus Hamlet stands with the social psychologists who use stooges acting out emotion to cause an emotional response in an uninformed or duped subject.

In his experiment Hamlet assumes, as he did earlier, that the guilty will respond differently from the "free" and that the king, if guilty, will alter his own emotional display, permitting Hamlet, the intent observer, to detect the physiological changes caused by guilt "if he but blench." Hamlet intends to use a play as social psychologists use stooges or as a psychophysiologist such as Lazarus might use a film depicting a subincision ritual (Lazarus 1966:144). The film or the actions of the stooge is used as a stimulus to produce an effect on the audience which is recorded as the outcome of the experiment. In such experiments real or theatrical events can be used interchangeably. A whole or a portion of the film or the play can be used (the king does not wait for the play's conclusion before leaving). The experimenter does not have to think about the interpretive strategies used by the audience; indeed, most investigators, like Hamlet, attribute an emotional meaning to the subject's behavior and assume that the subject responds to rather than interprets the film or the stooge's play. In most modern psychophysiological investigations, films and stooges can be used interchangeably with mechanical stimuli, like painful emotional shock, to produce emotional responses. A film can then be compared to a stimulus like an electric shock: a communication equated with a physical interaction. Hamlet creates the same kind of confusion by using the mime performance as if it were a natural event and constructing a causal chain of stimuli and responses in which the play is the stimulus and the king's actions the response.

The remainder of this paper will consider the confusions between intended communications and causally related interactions in the study of three related phenomena: dreams, hysteria, and hypnosis. Each of these phenomena can be related by causal interactions to other natural events. Each can be studied as communication. Rarely have investigators considered the utility of alternately making one and then the other assumption, and testing the results of such explorations against one another. All three events are particularly subject to the confusion of communication and interaction because they are essentially events that are seen and described in terms of what is seen. The confusion is inherent in events that are described by sight, by change in form, both because pictures are always edited, and the criteria for such editing usually remain unarticulated, and because anytime form changes, there are some aspects of that change which clearly cannot be shaped by our conscious intent. The paradox is perhaps most familiar in the study of dreams. 


\section{Dreams as Visual Events}

Dreams are essentially visual events. Dreams with only words do occur, and they have their own eerie character, but they are exceptional and notably in contrast with the almost invariantly visual nature of dream life. The logic of dreams is also the logic of pictures. Opposites are combined. The dreamer asleep watches the dreamer awake watching the dreamer murdered. People long dead come alive, and people alive are represented as dead. Night and day occur simultaneously, places change into each other faster than a dissolving cut in a film. Time has no fixed dimension and can be greatly contracted or expanded. Not only are dreams visual events, representations of ourselves and the world around us; they are also events which are anchored to definable physiological events: a particular pattern in the electroencephalogram, rapid back-and-forth movements of the eyes beneath closed eyelids, and a cessation of movement in the rest of the body. Since dreams have such a clearly representational character, and are associated with definable physiological events, they should have the character of signs or caused mental events. Indeed, we recognize a general agreement (no matter what variation there may be in the acceptability of particular theories about the meaning of dreams) that dreams are not intended by the dreamer, that they are in some way forced upon the dreamer, unlike reverie or daydreaming in which the dreamer, no matter how passive, is a willing accomplice. Dreams come from somewhere else and are not a product of our intentional or volitional consciousness. We recognize their alien character by our continual mystification about their meaning. We may consult a ten-cent dream book or a hundred-dollar-anhour psychoanalyst, or even a religious prophet without price, but we recognize the wisdom of searching out a hidden meaning.

If dreams seem to be a kind of natural event, the evidence of the working of part of our mind that is free from our own intentions, they should be ideal tools for the study of causal relationships within mental activity. Unfortunately, they are private events, and to be studied, the visual dream must be translated into words. This translation and the subsequent verbal operations used to discern the meaning of the dream permit the operation of intentional behavior to such an extent that we can no longer be sure that the translated dream, or even the dream as represented after the process of translation, still has the character of a natural event. It could just as well be an elegantly constructed performance reflecting the mutual intentions of dreamer and analyst. This ineluctable confusion of cause and intent is not merely the result of the translation of the dream from memories of visual events known only to the dreamer into words that can be shared by dreamer and analyst; it is intensified by the application of the only method we have for decoding dreams; psychoanalytic free association. This method makes the basic assumption that the dream is a disguised wish. The wish is "censored" but not eliminated by the partially aroused ego. The ego censors the wish in such a way that the wish is still represented and hence gratifying to the unconscious organ of the wishing activity, and yet the wish is sufficiently disguised that the anxieties of the ego are not overaroused. With this happy result, both mental organs achieve at least a partial satisfaction and sleep continues. The dream is assumed to be censored in a peculiar fashion: the representation of the wish is replaced by the representations of events or images associated with that wish, but different enough to effect a disguise.

The dream is decoded by searching for associations of the "manifest" dream that will be closer to the hidden wish and permit either the analyst or the patient to reconstruct that wish. To start the decoding process, the dream is broken into fragments and the patient free-associates to these fragments. The first part of this association may lead to the amplification of the verbal detail in which the dream is described, resulting in a change in the dream narrative. Fragments rather than dreams are used in the associative process, following Freud's dictum that a dream is more like a rebus than a poem (in a rebus, the visual representations spelling out the words of the message have no necessary associations with each other; Freud 1961 ed.). The dream is not required to have the unity of image required of a poem.

The free associations that are linked by the patient to the dream fragments are, of course, free from the conventions of narrative, free from intention, and hence causally related. These associations are assumed to be chains of thoughts or images that are not shaped into any conventional narrative sequence. Images, thoughts, ideas, and words can be linked by any one or more of the thousands of potential criteria for grouping percepts. The patient's associations are expected, with many false starts and diversions, to travel backward over the branching chains of associations to the hidden impulses that generated the dream. Thus after the associative process the dream consists of fragments, each surrounded by its own skein of interconnected chains of associations. This assembly is very much larger than the original dream narrative and, more importantly, very much larger than either the interpretation of the dream fragment offered by the psychiatrist or even the associations actually used to justify the interpretation. Dream images are assumed to be very condensed expressions of a potentially large group of associations available for disguised expression of the dream wish. Dream interpretations are very condensed expressions of a very long list of the patient's associations. This peculiarly symmetrical relationship-between, on one hand, a condensed dream and a large set of potential associations and, on the other, a condensed interpretation and a large set of the patient's actual associations-suggests a change in the name of the ego's dream maker, a change from dream censor to dream editor. 
The generation of dreams can be reimagined using the concept of editor. The editor has at its command all the chains of associations that have been built around a certain genera of wish. This is a very large pool of material stretching backward into the far and infantile past, very much larger than the chain of associations that a patient will uncover at any single analytic session devoted to dream analysis. In order to prevent an unacceptable wish from becoming conscious, the operator does not remove material; it searches the large file of related material until it finds images that are at a suitable distance along the chain to permit the disguise of the unacceptable wish but not at too great a distance to represent the wish at all. But using nodes, or places where chains cross, the operator can, by skillful editing, choose associations that are part of many different chains, achieving both condensation and the representation of contradictory or opposing concepts (the wish and its negation).

Another editing process begins as soon as the physiological events of dreaming are over. A sleeper remembers only a few of the many dreams he experiences during a night. Of those that are remembered on waking, only a few are brought to the analyst. In the course of an analysis, perhaps weeks or months go by without dreams being part of the analytic work. Of those dreams that are analyzed, few are analyzed completely; most dream analyses concern themselves with some but not all of the fragments. This condensation was described by Freud in his Introductory Lectures:

These last dreams provide splendid material and are in no respect inferior to those of healthy persons, but the technique of the treatment obliges us to subordinate dream-interpretation to therapeutic purposes and to desist from the attempt to interpret a large number of the dreams as soon as we have extracted from them something of use for the treatment. Again many dreams which occur during the treatment elude full interpretation altogether; since they have their origin in the whole mass of material in the mind which is as yet unknown to us....

The literature of psycho-analysis shows no lack of good and detailed dream-analyses; I myself have published some which formed part of the history of certain pathological cases. Perhaps the best example of a dream interpretation is that published by O. Rank, consisting of the analysis of two mutually related dreams of a young girl. These cover about two pages of print, while the analysis of them runs into 76 pages. [Freud 1943 ed.:163-164]

Some dreams that are analyzed in a satisfying way do not remain in the memory of either the patient or the analyst, and of the ones that do, only a few are recorded for discussion at meetings or published in the psychoanalytic literature. Although millions of analytic hours have passed since the publication of The Interpretation of Dreams, only a few thousand dreams and dream fragments are part of the analytic literature and available to shape our ideas about the interpretation of dreams.
From the natural event of REM sleep and dreaming by the patient to the published dreams which shape our ideas about the meaning of dreams, there is an editing ratio of millions to one. Because of the postulated editing activity within the dreamer, the editing and selective forgetting of dreams by the now-conscious dreamer, and the enormous condensation we have described between the dream in therapy and dreams in published accounts, we have no idea whether the analyst is more like a filmmaker editing his raw documentary footage into a filmic performance or a scientist recording the texture of natural events. The problem is confounded by our ignorance of the conventions and skills used by dream maker, patient, analyst, and editorial board in creating the edited material we are able to read. We cannot separate the laws of dream process from the conventions for analysis. of dreams and editing the analytic material. This inability to separate editorial convention from natural law is present any time we edit our pictures of reality from a large set of observations to a small set of illustrations.

For example, home photographs are pictures of the external realities of a person's life. We would like to use these objective representations of events to describe a historical reality for the families that took those pictures. Any person with a camera and the ability to use it has a potentially infinite number of sights and events that he could record with a "snapshot." Where a family does accumulate a large number of snapshots, relatively few of these are organized for social presentation. The inherent narrative or meaning within the ones that are organized cannot be understood directly but apparently requires the associations of the person who took the picture, associations which describe the occasion and purpose for taking the picture, and are part of a larger narrative the picture was designed to preserve. Ruby (1976) asserts that the snapshot is an "aide-mémoire" and is linked to a chain of narrative and the conventions for taking home photographs. Convention instructs the editing of visual images into filmic ones, and within that convention particular constellations of events give meaning to the pictures that are taken. Pictures must then be treated like the fragments of a dream, understood through recognition of the conventions of filming and the associations to particular film imaqes.

Just as analysts would like to use dreams to obtain a clear picture of the reality of the internal unconscious, just as social scientists would like to use home photographs to describe the objective realities of social relationships within a family, anthropologists, ethologists, and naturalists would like to use the photographs they take during their investigations to represent the reality of their observations to their readers. However, almost all those illustrative photographs are selected from a large corpus of photographs, and the method of making the selection is never articulated. In a recent review of a book on the life of one species of Japanese fox, the reviewer mentions with admiration that the tens of pictures 
in the book were selected from 70,000 photographs the author had taken in the course of his study (Breslin 1980:94). Since the technique of editing pictures to present reality is unarticulated by the observer, we do not know if those editorial processes are as conventional and undefined as the editing which permits the construction of the most unreal and dreamlike representations. When photographs or film are used in this fashion, we are always caught between convention and cause in our search for meaning. The intent of the observer can never be separated from the natural events he observes, and there will always be an unfortunate similarity between the dream and the documentary, or any other technique of representing reality in which pictures are selected to be placed side by side.

\section{Hysteria and Hypnosis}

Any natural event, even one so far removed from human intention as the explosion of a volcano, can be edited into a sequence of photographs that reflects more of the intent of the photographer and editor than the causal relationships between the components of the event. Yet there are some phenomena in which the confusion of natural event and performance are so ingrained that the audience cannot choose an appropriate strategy for the interpretation of the event. Two such events, hysteria and hypnosis, are intimately related to the dream and the display of human emotion. Freud's first psychological investigations were explorations in the therapy of hysteria, and in that therapy he first used and then abandoned the use of hypnosis. The associative techniques he used to puzzle out the meaning of hysterical symptoms were later used to analyze the images of dreams.

Both hypnosis and hysteria can be described as simulated, performed, or acted behavior, or, alternatively, as behavior "caused" by unconscious mental processes. Both are in large part dumb show, or mimed behavior, and we recognize their presence by looking at the form or motion of the body rather than the words used by the subject or patient. The hysteric does not tell the physician about his or her symptoms; he or she acts the part with fantastically contorted limbs, paralysis, convulsions, swoons, anaesthesias, blindness, or the inability to walk or talk. The hypnotic subject may not be called upon to speak at all. He or she sits, walks, or acts like a somnambulist, performing the part with anaesthesias, paralysis, floating limbs, rigid limbs, floppy limbs, and actions indicative of positive or negative hallucinations. If the hysteric only complained of aches and pains like a hypochondriac or a malingerer instead of acting out the illness, and if the hypnotized subject only told us he was in trance and generated no novel behavior, we would not believe the hysteric to be diseased and the hypnotic subject to be in an altered state of consciousness. These two phenomena are believable because they are, in large part, acted out. The acting, in the absence of words, permits us to define that behavior as a sign or a natural event and to dispense with the problem of assigning intent to the performance.

\section{Hysteria}

Charcot, the great nineteenth-century neurologist, brought the study of hysteria into the domain of neurological investigation by differentiating the "functional" convulsions of hysterical epilepsy from the convulsions of true epilepsy, which were associated with pathological change within the brain. The differentiation of real and "imitated" convulsions was made by observing the patient for signs of organic illness and distinguishing them from the signs of functional illness. The functional illness, which was thought to be caused and hence not intentional, was differentiated from malingering or intentional imitation of illness by demonstrating that the signs of hysterical illness could not be imitated by the "normal" individual.

The emphasis on signs, visual demonstrations of illness, rather than on words was the essential characteristic of scientific medicine of the nineteenth century. Charcot exemplified Foucault's conclusion that the perceptual organization of nineteenth-century medicine centered on the gaze of the clinician:

Clinical experience-that opening up of the concrete individual, for the first time in Western history, to the language of rationality, that major event in the relationship of man to himself and of language to things-was soon taken as a simple conceptualized confrontation of a gaze and a face, or a glance and a silent body; a sort of contract prior to all discourse, free of the burdens of language by which two living individuals are "trapped" in a common but non-reciprocal situation. [Foucault 1975: xv]

Charcot exemplified Foucault's clinician, and this exemplification was noted by his students and contemporaries, especially Freud:

He was not much given to cogitation, was not of the reflective type, but he had an artistically gifted temperament-as he said himself, he was a visuel, a seer. He himself told us the following about his method of working: he was accustomed to look again and again at things that were incomprehensible to him, to deepen his impression of them day by day, until suddenly understanding of them dawned upon him. [Zilboorg and Henry 1942: 362-364]

Charcot's interest in the visual extended beyond clinical observation. He was one of the first medical investigators to use photography as part of his research method. He brought Duchenne de Boulogne to the Salpetriere and with Duchenne's aid established a photographic laboratory. Duchenne published, in 1862, a photo- 
graphic study of facial expression, "Mecanisme de la physionomie humaine," which was one of those used by Darwin in illustrating The Expression of the Emotions in Man and Animals. Charcot went on to foster the publication of Bourneville and Regnard's "La grande hysterie; iconagraphie photographique de la Salpetrière." Charcot himself examined the representations of hysterical illness in art in "Les démoniaques dans l'art," which was succeeded by "Les difformes et les malades dans l'art" (Owen 1971).

The argument I am making about the role of behavioral signs in the interpretation of hysteria can be strengthened by noting Darwin's use of photographs in The Expression of the Emotions in Man and Animals and his struggle with the problem of intent. He used pictures of madmen and actors, one assumed to be acting unintentionally and the other intentionally. He used pictures, derived from Duchenne, of a real and a simulated smile, to distinguish between intended and inherited behavior. He expressed his conclusions as follows:

We will now consider how far the will and consciousness have come into play in the development of the various movements of expression. As far as we can judge, only a few expressive movements, such as those just referred to, are learnt by each individual; that is, were consciously and voluntarily performed during the early years of life for some definite object or in imitation of others, and then became habitual. The far greater number of the movements of expression, and all the more important ones, are, as we have seen, innate or inherited; and such cannot be said to depend on the will of the individual. [Darwin 1965 ed.: 352]

Although Charcot treated hysteria as a functional neurological disturbance, a true disease, he did recognize that the symptoms and signs were not without purpose, but represented an imitation of illness, and that the patients actively sought treatment for disease. Charcot spoke of a "mania operativea passiva" to describe the avidity of hysterics for surgery. Modern physicians talk of "compensation neurosis," implying that the hysterical symptoms are not only directed at seeking treatment but also at reaping the rewards of disability which is validated by treatment. When psychiatrists speak of hysteria, they recognize that the symptoms are imitations of illness and that the functional disturbance reflects not the anatomical mechanism of a limb or an organ but the patient's "idea" of a limb or an organ. Thus hysterical anaesthesia of the hand does not follow the anatomic pathways of nerves (unless the patient is a physician or a nurse and knows the anatomy of nerves and muscles) but follows the patient's representation of a hand-the anaesthesia ceasing at the wrist, having the form of a glove. Physicians of Charcot's time also recognized that hysterical symptoms changed with patients' ideas about iliness and the function of limbs. Now psychiatrists no longer see the grand hysterical seizures that Charcot demonstrated to the medical audiences of the Salpet- rière. Modern hysterical symptoms reflect modern ideas about illness. The fact that the patient presents his or her self as a patient seeking help with an illness, and the fact that the patient acts out the illness, constructs the dilemma for the physician. Is it simulation or is it real?

Freud, unlike Charcot, did not study the form of hysterical illness. He treated hysterical symptoms as he later treated dream images. He had the patient translate them into words, then built associations upon those words until the patient put into words the repressed traumatic memory that was the "cause" of the symptoms. The symptoms, caused by unconscious repressed images, ceased being causes when they were translated into words. Freud in his cathartic therapy respected the distinction between words which are intended behavior and images which are signs or natural events. The translation of a repressed image into words deprives that image of its power to "cause."

\section{Hypnosis}

From the time of its introduction by Mesmer, hypnosis seems to be a kind of behavior display which is caused by some force exterior to the subject's will. The behavior of the hypnotic subject as seen and described by the hypnotist or the observer seems to be caused by a force that is normally not operative when the subject is in his normal state. Mesmer believed, or said he believed, that the hypnotic phenomenon was caused by the influence of magnets. He first used real magnets to induce the state, later used objects that were treated by exposure to magnets, and still later developed the idea that living bodies have a kind of magnetic force he called "animal magnetism." He believed that the passage of his hands over the patient caused changes in the magnetic forces within the body, producing the results he observed. His subjects twitched and convulsed upon entering the hypnotic state, a behavior linked in Mesmer's mind with the twitching of a limb when a nerve is electrically stimulated.

Mesmer's detractors, however, observed the public performances at which he produced his trances and saw his patients' behavior in terms of suggestion, acting, and imitation. A royal commission was appointed to decide on the reality of the phenomenon. They proposed sophisticated social psychological experiments in which patients would be blindfolded and unaware of the identity of the person treating them or the object used to treat them. Mesmer refused to be part of these experiments, and the commission made its report without them. They concluded:

The commissioners, having found that the fluid animal magnetism can not be perceived by any of the senses and that it has no effect upon themselves or upon the patients submitted to them; having assured themselves that pressure and contact produce changes that are seldom favorable in 
the organic economy and agitations which are always unfavourable, in the imagination; having finally demonstrated by decisive experiments that imagination without magnetism produces convulsions and that magnetism without imagination produces nothing; they have unanimously concluded, on the question of the existence and the utility of magnetism, that there is no proof of its existence, that this fluid without existence is consequently without utility, and that the violent effects observed in public clinics are to be attributed to the touching, to the aroused imagination, and to that mechanical imitation which lead us, in spite of ourselves, to repeat that which strikes our senses. ... touching, and the repeated action of the imagination for the purpose of producing crises can be harmful, that the sight of these crises is likewise dangerous because of the imitation which nature seems to have imposed upon us as a law.... [Pattie 1967:21]

The causal action of natural events is rejected in favor of imagination and imitation. For them hypnosis was a performance, but a strange kind of performance. Their last sentence in the quoted portion of their text, "imitation which nature seems to have imposed upon us as a law, " takes the problem full round, much in the manner of the psychoanalytic definition of hysteria, by proposing that the imitation was not an intended act but an imposition of natural law. They both denied and asserted the naturalness or lawfulness of the performance. This ambivalence about hypnosis still persists and troubles the most sophisticated of the social psychologists who study hypnotic phenomena.

Hypnosis and hysteria were united by Charcot, who used hypnosis both to evoke and to terminate hysterical symptoms and who defined hypnosis as an artificial form of hysteria, a temporary neurosis caused by the hypnotist. The play of hypnosis and hysteria can be illustrated in this account of the hypnosis of a female hysteric, "Greuz":

After this preamble Charcot proceeded to introduce a hysterical girl, "Greuz," who had a left hemianesthesia with full sensibility on the right side. Charcot remarked that she had been subjected to hypnotism on only four or five occasions. . .

Greuz was put into somnambulism. "Your right hand is paralyzed," said Charcot firmly. Greuz demurred, saying Charcot was mistaken. But Charcot insisted in an accent of authority, and after a few minutes of this discussion, the hand hung flaccidly. All active movement of the arm was abolished, as well as all resistance to passive movements. Very interestingly, the hand, the arm, the shoulder and part of the chest-previously normal-now showed complete anesthesia. The genuineness of the anesthesia was verified by demonstrating to the class that violent torsion of the joints produced no sign of feeling, and that no pain or sensation was evident in Greuz's face on faradizing the nerve trunks of the arm even to the extent of causing violent contraction of the muscles. Charcot now pointed out to the class, with a certain air of justifiable satisfaction, that the symptoms produced artificially under hypnosis in Greuz were in almost all respects identical with those occurring as hysterical symptoms in the previously mentioned patients Pen. and Porcz. [Owen 1971:118-119]

In reading the account of the patient Greuz, it is perhaps too easy to assume that Charcot was being deceived by the patient, especially when we recognize the implications of the statement that the patient had "only" been hypnotized three or four times previously. Yet Charcot was an astute observer, and many of his observations stand as part of our neurological and psychiatric knowledge. To illustrate that hysteria and hypnosis are still entwined phenomena let me cite an example from my own practice. I had been treating a patient with a classic hysterical conversion reaction which in her case consisted of hysterical epileptiform seizures, an ataxic gait, and a speech disturbance. During that time we had slowly withdrawn her medication for epilepsy, which included phenobarbital. The withdrawal of barbiturate medication can cause severe symptoms including tremors, agitation, stereotyped ticklike movements, motor incoordination, convulsions, and, in some instances, a series of convulsions terminating in death. After the last and lowest dose of medication had been stopped, she was well for two days but then was brought at her own request to the local hospital. The resident in charge of admissions called me and informed me that the patient had the classical symptoms of barbiturate withdrawal and that she required hospitalization for remedication. I described the care with which the medication was withdrawn and my diagnosis, conversion hysteria or simulated illness. He then changed his diagnosis from real illness to simulated illness and suggested psychiatric hospitalization. The family then asked me to see the patient. She was brought in by four of her family, hardly able to walk, arms and legs flailing about as she struggled to regain her balance, unable to talk, except in a voice so slurred as to be almost unintelligible, sounding for all the world like a drunk about to lapse into alcoholic coma, and picking and scratching at her skin in the classic manner of someone in barbiturate withdrawal. With her family seated about the consultation room, I ordered her to sit down, told her to fix her eyes on "a spot where the ceiling joins the wall," and began a conventional trance induction suggesting relaxation and "deep' trance. Within thirty seconds all her tremors ceased. She seemed deeply relaxed in another five minutes. I awoke her from the trance; her speech was normal, and she was able to walk out of the room unassisted, with her bewildered relatives following.

What had happened? What was real? What was unconscious behavior? What was conscious? What was intended? What was not? To answer one question, the patient was a nurse who had worked in psychiatric services and therefore had enough information to mimic barbiturate withdrawal symptoms. It was possible for her to "in- 
tend" all the behavior she manifested. Given our knowledge of this ability we have to make a decision about the performance or the two performances, the performance as a patient with barbiturate withdrawal symptoms and the performance as a hypnotized subject loosing the symptoms of a hysterical neurosis. The first performance had three separate audiences: the resident at the local hospital, the family, and me. The second had only two, unless the patient is to be counted as both audience and performer. The last parenthetical thought is no simple aside. If one believes that hypnosis is a psychobiological phenomenon, and that the intent is not conscious intent but unconscious intent, then the patient is an audience to her own performance. And the patient expresses the same wonderment as the other audiences and acts as if he or she has been watching an event much the same way as a patient might watch an operation being performed on his or her abdomen through a mirror.

The subjects of Charcot were demonstrated on the stage of amphitheaters with an audience of visiting medical scholars, students, interns, and house staff. The patients were in almost perpetual care in the hospital, were used over and over again in lecture demonstrations, and were trained in other sessions in which subordinate staff would practice the uncovering of the same phenomenon demonstrated by the professor. More importantly, patients were trained for the grand performance by being hypnotized by the house staff to determine if they were of sufficient interest to be displayed at lectures. Apparently Charcot himself, impressed by the visual impact of demonstration, practiced the mimicry of patients' symptoms and incorporated acted symptoms into his own lecture repertoire.

The three patients used most often by Charcot were trained by the descendants of one school of animal magnetism. They had been trained so well that they exhibited an invariant form of hypnotic behavior-they knew their lines too well, and Charcot made the mistake of confusing an invariant performance for an invariant psychological or psychobiological law. He described rigid stages of hypnosis which were not seen outside the Salpetrière by investigators who did not have the same trained subjects. Janet, a contemporary of Charcot, recognized that Charcot was dealing with trained performers. Janet was able to do so because he could elicit Charcot's stages of hypnosis from only one subject. That subject was a trained somnambulist used in stage demonstrations and trained for the stage by the same school of animal magnetizers that trained Charcot's patients (Owen 1971:155).

We now recognize the correctness of Janet's insights. The stages of hypnosis described by Charcot were welllearned parts of his patients' performance. Different patients, then and now, have their own performances. There are no apparent "natural laws" governing the behavior of hypnotic subjects, and what a subject believes is part of hypnosis usually becomes a part of his hypnotic performance. We are left agreeing with the conclusions of the commission that investigated Mesmer's hypnosis: it succeeds more from imitation than from physical force. Yet upon looking at the kinds of behaviors included in these subjects' repertoire, everyone finds it hard to accept the conclusion that it was all an act with nothing "real" embedded in the performance.

This paradox still plagues the study of hypnosis. Martin Orne (1972) and Theodore Barber (1967) have used exemplary experimental techniques to demonstrate that it is not possible to distinguish people simulating hypnosis from people who are deeply hypnotized. Both kinds of subjects can accomplish the same feats, stiffen limbs, act as if limbs are paralyzed, appear to regress in age, stiffen their bodies so that they can be supported by two chairs and have someone stand on their abdomen, and so on. Trained hypnotists cannot detect the deception, yet simulators always know they are simulating. These studies leave the investigators with an interesting paradox: If all the events of hypnosis could be simulated by a motivated subject, and if there were nothing "left over" that he could not simulate or include in his repertoire of conscious intended behavior, then hypnosis is nothing more than a social convention, a performance of the subject and the hypnotist for each other and any audience present. Hypnosis defined as a social convention does not require that there be any causal interaction between the behavior of the hypnotist and the "unconscious" or any other portion of the subject's mind not governed by intent. Without special attributes that could not be simulated, hypnosis might be a useful social convention for anxiety relief or enhancement of memory, but it could not be a kind of psychological interaction indicating causal relationships between social acts and unconscious motivational structures of the subject's mind.

Barber (1967) has been willing to accept hypnosis as a mere social convention, but Orne (1972) has attempted to find something more than simulation that could be an essential characteristic of the hypnotic state, free from the intent of the subject. His demonstration of essential characteristics of hypnosis is interesting but far from convincing. He arrived at the conclusion that hypnotic subjects use a special kind of logic called trance logic. The following circumstances would be an example.

A subject is told to hallucinate a person sitting in an empty chair. He is then told to sit in that chair. The simulator operating under those commands will sit on the edge of the chair as if he were sharing the chair with another. He indicates that he recognizes the incompatibility of two people occupying the same chair at once. The truly hypnotized subject will sit directly and squarely on the chair. He sees no incompatibility with two people simultaneously occupying the same space at the same time. Trance logic operates in the same way as the unconscious mind. It is capable of asserting both of two in- 
compatible statements simultaneously. In trance logic, as in dream and the unconscious, it can rain and not rain at the same time. One can be living and dead at the same time. One can watch one's self from a distance. The kind of logic called trance logic is not only the logic of the unconscious and the representation of the unconscious called dreams, or the characteristic of the hypnotic state, it is, as we have stated earlier, characteristic of the logic of pictures. The essence of hypnosis seems to be much like the essence of dreams, and both seem to owe some of their character to the ways in which visual images carry meaning.

The psychological investigators who have attempted to see if there is more than simulation in hypnosis have also used new strategies in interpreting their subjects' behavior. In attempting to see if their subjects were ruled by psychological cause and effect, they have attempted to rule out the operation of intent and, specifically, tried to rule out the possibility that the subject is performing for the experimenter. They have tried to determine if the elegant performances they use to "stimulate" their subjects might be perceived as performance by the subject. Their concern is not so much the penetration of their deception, but the prospect that the subject might interpret the performance and define a role for himself. Orne (1972: 399-444) developed the twin ideas of "demand characteristics of the experiment" and "quasi-control" to deal with this process. The demand characteristics of the experiments are those aspects of the experimental performance that indicate the subject's role or tell the subject how the experimenter wants him to behave. The quasi-control is a set of procedures which are used to determine if the subject is correctly informed about the experimenter's intent. If the subject knows how he should perform, then the operation of psychological law can never be determined by that experiment. The experimenter is constructing a performance to communicate with a subject, and the subject is performing for the experimenter. Only if the subject cannot guess how he should perform, can the experiment be used to discern psychological reality.
Unfortunately the investigation of intent in the study of hypnosis and other "psychological interactions" is difficult for investigators because they do not wish to study communication and because they are alarmed by the proposition that where there is communication there is no cause and effect. Rosenhan has described the tacit conspiracy in which subjects and experimenters conceal from each other their knowledge that they are performers and audiences:

The term "muted awareness" designates the phenomenon whereby subjects in many experiments sense what is expected of them, sense also that they are not supposed to have this awareness, and behave accordingly. Thus, on brief or unsophisticated inquiry, subjects will often deny that they have "intuited" the main hypotheses of the experiment or that they have understood the purpose of the experimental manipulations. The denial satisfies their need to be "good" subjects and at the same time satisfies the experimenter that he has concealed his biases. Thus, a pact of naivete is established [Orne terms it a pact of ignorance], with both parties sufficiently invested to play their roles well and to retain their secrets. [Rosenhan 1967:487]

We can still wonder with Darwin and Hamlet that simulated emotion embedded in an actor's performance can change the way in which people behave. We cannot, however, forget that performance and reality are two aspects of any social event, and failure to see the performance as a performance does not construct a reality.

This paper has made a simple argument about three troublesome events, dreams, hysteria, and hypnosis. These events cannot be studied as either a performance or a natural event. We increase our knowledge of these phenomena by alternately studying them as if they were intended and as if they were unintended. We must recognize that they are both performance and reality. The necessary logic of these events, which calls for such a dual strategy for interpretation, is in part determined by the logic of visual events: images, pictures, and observations about human behavior that rely on visual impressions. The peculiar character of dreams, hysteria, and hypnosis, and their ability to include such a high order of contradiction, is characteristic of the logic of pictures. In the interpretation of dreams, the ability of dreams to be so allusive and evocative and carry such a high order of meaningful contradiction is augmented by the editorial process that occurs when we construct a dream or an interpretation of a dream. One conclusion which follows from this argument, but which will have to be justified in another paper, is that much of what we feel is peculiar to unconscious thought, and the logic of unconscious thinking, derives from the simple fact that the unconscious thinks in pictures. 


\section{References}

- Barber, Theodore X.

1967 "Hypnotic" Phenomena: A Critique of Experimental Methods. In A Handbook of Clinical and Experimental Hypnosis. Jesse E. Gordon, ed. Pp. 444-480. New York: Macmillan.

- Breslin Carol

1980 The Foxes of Hokkaido: Book Review of Fox Family by Minoru Taketazu. Natural History, March 1980.

- Darwin, Charles

1965 The Expression of the Emotions in Man and Animals. Chicago: University of Chicago Press

- Foucault, Michel

1975 The Birth of the Clinic: An Archaeology of Medical Perception. New York: Random House.

- Freud, Sigmund

1943 A General Introduction to Psychoanalysis. Joan Riviere, ed. Garden City, N.Y.: Garden City Publishing Co.

1961 The Interpretation of Dreams. James Strachey, ed. Chapter 6. New York: Science Editions.

- Lazarus, Richard

1966 Psychological Stress and the Coping Process. New York: McGraw-Hill.

- Orne, Martin

1972 On the Simulating Subject as a Quasi-Control Group in Hypnosis Research: What, Why, and How. In Hypnosis. Erika Fromm and Ronald Shore, eds. Chicago: Aldine Atherton.

- Owen, A. R. G.

1971 Hysteria, Hypnosis, and Healing: The Work of J. M. Charcot. London: Dennis Dobson.

- Pattie, Frank

1967 A Brief History of Hypnosis. In A Handbook of Clinical and Experimental Hypnosis. Jesse E. Gordon, ed. New York: Macmillan.

- Rosenhan, David

1967 On the Social Psychology of Hypnosis Research. In A Handbook of Clinical and Experimental Hypnosis. Jesse E. Gordon, ed. New York: Macmillan.

- Ruby, Jay

1976 In a Pic's Eye: Interpretative Strategies for Deriving Significance and Meaning from Photographs. Afterimage 3(9).

- Shakespeare, William

1965 The Complete Works of William Shakespeare. New York: Avenel Books.

- Worth, Sol

1975 Pictures Can't Say Ain't. Versus 12:85-108.

- and Larry Gross

1974 Symbolic Strategies. Journal of Communication 24(4):2739.

- Zilboorg, Gregory, and G. W. Henry

1942 History of Medical Psychology. New York: Norton. 